\title{
Que Química! Entre o Fascínio Pelo Pessimismo e a Hesitação Perante o Optimismo*
}

\author{
Sérgio P. J. Rodrigues \\ Centro de Química de Coimbra; Departamento de Química, Universidade de Coimbra \\ spjrodrigues@ci.uc.pt
}

\begin{abstract}
What Chemistry! Between the Fascination with Pessimism and the Faltering Before Optimism - In the present work, some aspects of (supposedly) controversial contributions of chemistry to our world, as well as dilemmas raised by this science, are analyzed. From classical Haber and Bosch's synthetic fertilizers to the ozone hole and global warming, passing on the use of pesticides and the presence of plastics and microplastics in the ocean, different (optimistic and pessimistic) perspectives are tackled. Prejudices about natural, synthetic and artificial compounds and materials will also be discussed.
\end{abstract}

$\mathrm{N}$ o presente trabalho são analisados alguns dos aspectos (aparentemente) controversos das contribuições da química para o mundo actual e dos dilemas levantados por esta ciência. Dos adubos sintéticos de Haber e Bosch ao buraco de ozono e aquecimento global, passando pelo uso de pesticidas e a presença de plásticos e microplásticos nos oceanos, serão abordadas diferentes perspectivas (optimistas e pessimistas) existentes actualmente. Serão ainda discutidos os preconceitos que existem hoje em relação aos compostos e materiais naturais, sintéticos e artificiais.

\section{INTRODUÇÃO}

No poema Compost, cujos versos Que química! se tomam emprestados para o título, Walt Whitman apresenta uma visão optimista da química, da natureza e da acção humana sobre a natureza [1]. No entanto, a partir de meados do século XX essa visão foi-se tornando cada vez mais pessimista, e, a partir dos anos 60, associada, por vezes [2], à publicação de "Primavera Silenciosa" de Rachel Carson [3], generalizou-se uma atitude que alguns autores têm classificado como de quimiofobia [4]. Mais recentemente, apesar dos grandes avanços na resolução de problemas como o do buraco do ozono e das melhorias claras na qualidade de vida das pessoas (veja-se, e.g., [5,6]), tornou-se quase senso comum o empastelamento da química com algumas visões catastrofistas globais do mundo (veja-se, e.g., [1,7]). No entanto, mais recentemente, um estudo da Royal Society of Chemistry [8] revelou uma atitude muito mais favorável do público.

Ao longo da história humana sempre existiram visões catastrofistas e optimistas. E sempre ocorreu o apogeu e o declínio de civilizações, muitas vezes sem qualquer correlação com essas visões. Também, quase sempre os homens sentiram que estavam no fim da história, não conseguindo prever as transições que se seguiram. A ciência, que no final do século XIX parecia acabada, pelo menos através da retórica progressista e positivista (mas também das visões pessimistas) foi enriquecida com um número impressionante de descobertas e invenções inimagináveis à altura. Actualmente, com a omnipresença e desenvolvimento sem precedentes da ciência e da tecnologia não estamos, no en-

\footnotetext{
* Baseado, em parte, na comunicação apresentada no Colóquio "Educação em Ciências” realizado nos dias 3 e 4 de Julho de 2015 no Museu da Ciência da Universidade de Coimbra para uma audiência maioritária de professores de Biologia e Geologia do ensino secundário.
}

tanto, muito melhor do que os nossos antepassados no que concerne a visões catastrofistas e optimistas e à capacidade de previsão do futuro. Temos, claro, modelos científicos cada vez mais sofisticados e rigorosos de previsão, mas como tememos estar, desta vez com muito maior certeza científica, mesmo no fim da história, esses modelos parecem ser definitivos, podendo, claro, não o ser. E, na verdade, paradoxalmente, quanto mais respostas encontramos mais perguntas surgem.

Para o habitante do início do século Xx, morrer de gripe pneumónica, febre tifóide, difteria, tuberculose, ou de outras doenças comuns, ou até de causas vagas a que se atribuíam nomes como apoplexia era uma tragédia pessoal, claro, mas uma inevitabilidade. As deficientes condições de higiene e saneamento e a fome eram causas comuns de morte. No entanto, embora a esperança de vida fosse quase metade da actual, o crescimento da população mundial era já exponencial e começou a ser visto como uma ameaça à sustentabilidade do planeta.

Os problemas da fome e das doenças têm sido resolvidos de forma científica, com grande contribuição da química, embora as soluções existentes não estejam tão bem distribuídas pelo planeta como gostaríamos, ou em alguns casos acabem por criar novos problemas. Em qualquer dos casos, é indubitável que estamos actualmente muito melhor que no início do século XX (veja-se, e.g., [9]). No entanto, é consensual que existem actualmente muitos motivos para estarmos preocupados com o futuro (veja-se, e.g, [10]). Esta preocupação com o futuro do planeta é também um tema central na recente encíclica do Papa Francisco [11].

No presente texto irei referir um conjunto de aspectos, mais ou menos controversos, ligados à química directa ou indirectamente, os quais podem ser vistos de forma pessi- 
mista ou optimista. Dada a complexidade dos temas abordados, o tratamento seguido é necessariamente resumido, incompleto e passível de conter imprecisões. No entanto, penso que vale a pena correr o risco de abordar estes temas, enfrentando a desinformação e as críticas que muitas vezes são dirigidas de forma injusta à química. Centro-me no descontentamento em relação à componente utilitária da química [2], deixando de fora outras discussões que desvalorizam a química por se apresentar - ou poder ser - uma ciência essencialmente aplicada e utilitária. Na verdade, a química, apesar de algumas dificuldades formais e históricas [2] - e todas as ciências as têm -, é sem dúvida uma ciência fundamental e humanista, enfrentando problemas científicos fundamentais, que não é redutível à física, nem tem como principal objectivo o utilitarismo ou o serviço às outras ciências.

\section{DA UTILIDADE À POLUIÇÃO SEM PERDER DE VISTA A SUS- TENTABILIDADE}

A revolução dos plásticos e compostos sintéticos que ocorreu no século Xx foi extremamente importante para o bem-estar da humanidade, e, o que pode parecer paradoxal, tem sido também importante para a sustentabilidade do planeta. De facto, muitos plásticos e compostos sintéticos vieram substituir usos que embora renováveis eram escassos, corriam o risco de se extinguir, ou eram pouco eficientes nos processos de produção. Entre os muitos exemplos [6], podemos referir os tecidos sintéticos que vieram libertar muitos espaços agrícolas para outros fins e o emprego de polímeros que vieram substituir o uso de peles e órgãos de animais, metais e madeiras. Ou ainda o fim da caça às baleias para se obter óleos, marfim e componentes de perfumes, ou da caça aos elefantes de onde se obtinha o marfim para fazer bolas de bilhar. Todos esses produtos foram substituídos por equivalentes sintéticos ou obtidos de outras origens mais sustentáveis, com a ajuda da química. Os plásticos e os aglomerados de madeiras vieram substituir muitos usos de madeiras exóticas e o desperdício insustentável de árvores. Também as quantidades de vanilina, índigo (corante usado nas calças de ganga), ácido ascórbico (vitamina C), e outros compostos que usamos não seriam sustentáveis se fossem obtidas de forma tradicional. Acrescente-se o tendencial uso mais eficiente e menos poluente dos combustíveis. No entanto, embora tendencialmente mais eficientes e, em teoria, mais sustentáveis, estes avanços redundaram no aumento da poluição. Porquê? O principal problema do século XX foi um aumento exagerado das quantidades produzidas e das necessidades, a par com o aumento da população, o que levou inevitavelmente ao aumento da poluição. Para além disso, muitas comodidades e descobertas criaram necessidades discutíveis, abriram o caminho para o consumismo moderno. Esses aspectos estão muito patentes no pessimismo da literatura do século Xx (veja-se, e.g., $[1,7])$.

Um dos mais conhecidos e mediatizados problemas de poluição que enfrentamos são as grandes quantidades de plásticos que flutuam nos mares [12]. E o mais grave não são os plásticos intactos, ou os grandes fragmentos inestéticos que fazem ilhas artificiais, ou que se acumulam nas praias paradisíacas, como as Maldivas, ou que são ingeridos e se prendem aos animais marinhos - embora todos esses problemas sejam preocupantes. O principal problema são os microplásticos [13], fragmentos minúsculos de plástico que resultam da degradação dos fragmentos maiores ou que foram parar aos oceanos já nessa forma (por exemplo vindos de cremes esfoliantes) e que aumentam a turvação dos oceanos, diminuem a luz das camadas inferiores do oceano, entre outros problemas. Saber como estes plásticos foram lá parar tem uma resposta mais ou menos surpreendente: foram lançados no litoral, ou caíram, ou foram atirados de barcos. Por isso, hoje em dia há um grande controlo sobre os barcos que circulam e uma procura activa de solução para este problema, para o qual a química fará parte da solução com certeza. Para além da redução drástica e da degradação natural tanto biológica como química, podem procurar-se soluções de recolha ou reciclagem local. Paralelamente, a química tem vindo a desenvolver plásticos que são mais sustentáveis e biodegradáveis, através dos conceitos e métodos da Química Verde [14].

Para além da sua importância óbvia para a vida, o mar é, em particular, uma fonte potencial e muito importante de novos compostos e novos medicamentos [15]. É uma trivialidade dizê-lo, mas há fortes razões económicas e científicas para se preservarem os oceanos.

Um material que costuma ser associado à química é o crude, ou petróleo em bruto, extraído em boa parte no mar e também transportado por mar. São, assim, tristemente célebres as marés negras resultantes de acidentes e fugas de petróleo. No entanto, uma análise das quantidades derramadas (ver Figura 1), mostra que estas têm vindo a diminuir, fruto do maior cuidado dos operadores, maior rigor da legislação internacional e, claro, pressão da opinião pública. Apesar disso, em 2010, ocorreu na Flórida um dos maiores acidentes de que há memória (assinalado a vermelho no gráfico).

A companhia petrolífera envolvida inicialmente recusou ajuda para em seguida reconhecer não ter capacidade para resolver o problema e, posteriormente, ser obrigada a aceitar as responsabilidades. Não sabemos se as coisas poderiam ter ocorrido de outra forma. Muitos dos processos seguidos para conter o petróleo, como o uso de surfactantes, poderão acabar por se revelar ainda mais prejudiciais e ainda vai demorar bastante tempo a normalizar a situação ambiental na região. A pressão da opinião pública foi bastante forte e as companhias sabem que actualmente não podem ter o público contra elas, em especial quando não há dúvidas sobre as suas responsabilidades. A esse propósito vale a pena referir um incidente de 1995 [17] bastante mais complexo, embora muito menos dramático em termos ambientais. Uma companhia que pretendeu afundar uma plataforma petrolífera em fim de vida foi alvo de um boicote generalizado e obrigada a desmantelar essa plataforma em terra. Além de ter ficado muito mais caro (o que não é relevante para o público), a principal questão é que não se ficou a saber se era ou não ambientalmente mais seguro 


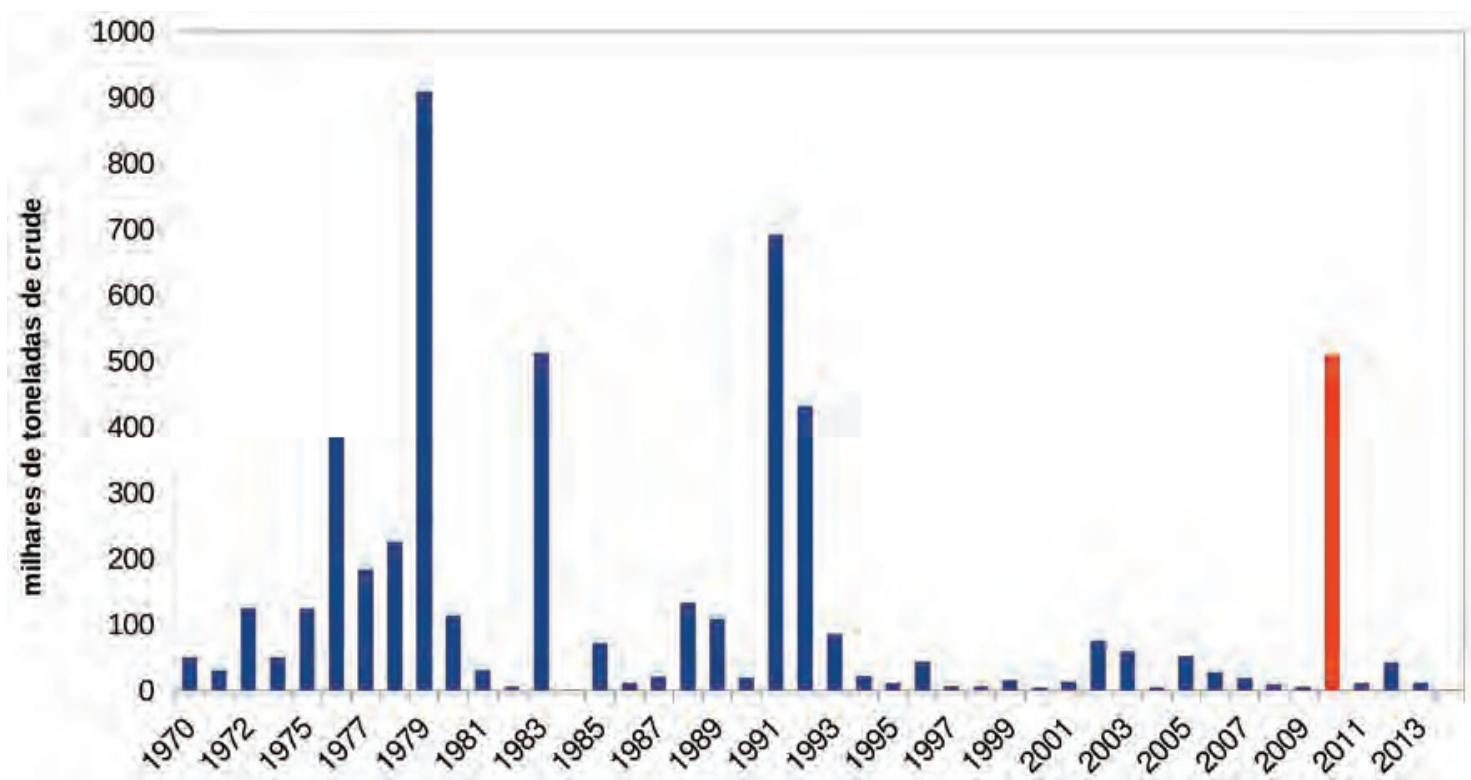

Figura 1 - Derrames de petróleo de 1970 a 2014 em milhares de toneladas de crude [16]

[17]. Entretanto, a União Europeia decidiu em 1998 que todas as instalações petrolíferas colocadas no mar teriam de ser completamente retiradas no final da sua utilização [18]. Mas nem tudo o que é afundado no mar parece ser considerado nocivo; recentemente foram afundados antigos barcos de guerra com o objectivo de servir de abrigo a peixes e atracção para mergulho recreativo [19].

Tentamos minimizar os derrames de petróleo, mas ainda não conseguimos viver sem ele. Todos os dias milhões de automóveis circulam pelas cidades, sendo estes a maior fonte de poluição das cidades. Mesmo com os catalisadores que minimizam os óxidos de nitrogénio e monóxido de carbono, os filtros de partículas e motores mais eficientes e optimizados. O problema é que são muitos carros (em Portugal cerca de dois milhões e seiscentos mil segundo dados do INE) e nem todos estão nas melhores condições; se a combustão fosse perfeita só sairia dos escapes água e dióxido de carbono. O fumo branco que se vê sair dos carros consiste essencialmente em gotículas de água e cada vez se vêem menos carros a libertar fumos negros e azulados, como era comum há décadas atrás. Também as chaminés das fábricas emitem fumos brancos de água em vez de fumos negros como acontecia antigamente. Os filtros, os catalisadores e outros desenvolvimentos estão a tornar as combustões dos derivados do petróleo mais eficientes, libertando quase só dióxido de carbono e água.

Infelizmente, o dióxido de carbono libertado de forma massiva por automóveis e algumas fábricas começa também a ser prejudicial, contribuindo para o denominado aumento do efeito de estufa. Espera-se que os combustíveis fósseis tenham nas próximas décadas uma importância menor em termos energéticos, começando a ser substituídos por fontes renováveis. Uma das grandes esperanças é a chamada economia do hidrogénio [20]. No entanto, embora o problema dos motores a hidrogénio esteja resolvido, estão ainda longe de solução eficiente, prática e competitiva o armazenamento e produção de hidrogénio [20].

Em qualquer dos casos, como referido acima, as fábricas e indústrias químicas modernas, assim como os carros actuais mais eficientes, pouco têm que ver com o fumo e poluição de há décadas atrás. Devido aos catalisadores diminuiu drasticamente o smog que era causado pelos óxidos de nitrogénio. Os carros deixaram de usar gasolinas com chumbo na forma de tetraetilchumbo (Figura 2, 1), o qual era usado para aumentar o seu poder detonante desde a década de 1920, diminuindo assim drasticamente a exposição a este metal tóxico. Para além disso, a quantidade de hidrocarbonetos aromáticos e outros compostos cancerígenos é limitada. Sendo assim, como se mantém o poder detonante das gasolinas? Por um lado com motores mais eficientes e por outro com novos aditivos. Em Portugal, as gasolinas têm até 15\% de MTBE (éter metil-terc-butílico, Figura 2, 2) como aditivo.

Na sequência da apresentação foi colocada a questão dos combustíveis aditivados e simples. Com base nas concentrações anunciadas pelas empresas (nalguns casos com va-

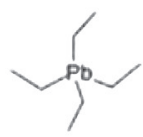

1

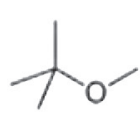

2

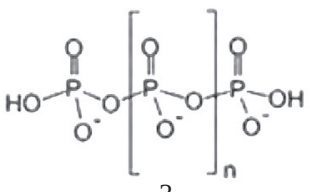

3

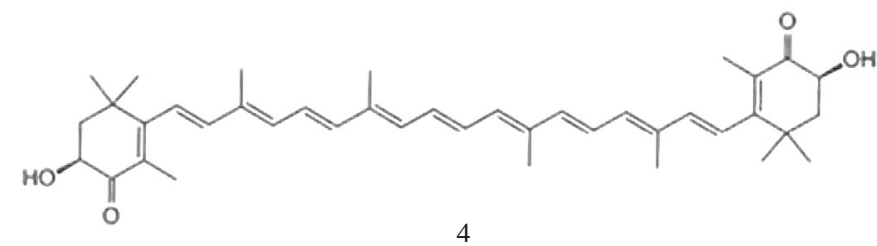

4

Figura 2 - Estruturas de algumas espécies químicas artificiais (1 tetraetilchumbo e 2 éter metil-terc-butílico) e naturais (3 polifosfatos e 4 astaxantina) referidas no texto 
lores da ordem de 0,1-1,5 mg/L) indiquei que esses aditivos não poderiam, em princípio, ter grande influência nas propriedades dos combustíveis, mas é necessário ter mais informação. Infelizmente, nenhuma das empresas contactadas respondeu às questões que lhes coloquei.

\section{Problemas e soluções globais mais ou menos co- NHECIDOS}

Voltando à questão do dióxido de carbono emitido pelos automóveis, a maioria dos investigadores sobre o clima está convencida de que o aumento do efeito de estufa está relacionado com a actividade humana e com a combustão de hidrocarbonetos, mas há ainda 3\% que têm dúvidas sobre isso [21]. Há ainda mais consenso sobre a ocorrência de um aquecimento global médio. Este apresenta, no entanto, flutuações. Por exemplo, grandes massas de gelo que estavam em fusão desde 1970 duplicaram de área de 2012 para 2013.

Um outro problema planetário é o do buraco da camada de ozono que se relacionou com os CFC (clorofluorocarbonetos) e levou ao abandono destes últimos e à sua substituição por outros compostos. Neste caso foi possível encontrar uma solução relativamente simples, não acontecendo o mesmo com o aquecimento global.

Embora sejam hoje reconhecidos como nocivos para a camada de ozono, os CFC foram uma invenção de grande importância que permitiu levar a refrigeração (o seu uso mais importante era nos frigoríficos) à generalidade da população. Com isso foram com certeza salvas muitas vidas através da diminuição das intoxicações alimentares e outras doenças. Curiosamente, o seu inventor foi o mesmo da gasolina com chumbo, Thomas Midgley, Jr. Este inventor não tinha qualquer possibilidade de suspeitar do problema do buraco do ozono, contrariamente à toxicidade do chumbo que era já bem conhecida.

Os gelos da Antártida revelam efeitos da industrialização humana, mostrando um aumento da presença de chumbo desde 1898 [22]. No entanto, essa descoberta não é por si só um indício de um problema ambiental preocupante. Embora as concentrações tenham aumentado para valores até cerca de 6 pg/g em relação ao valor médio de 2,12 pg/g de referência, os valores medidos são milhares de vezes inferiores ao threshold limit value (TLV) na água $(0,01 \mathrm{mg} / \mathrm{L}$, correspondente a $10000 \mathrm{pg} / \mathrm{g}$ ) e centenas de vezes inferiores ao do ar $\left(0,5 \mu \mathrm{g} / \mathrm{m}^{3}\right)$. Estes valores contrastam tristemente com uma contaminação recente e muito preocupante das águas de consumo humano, devido a canalizações com chumbo numa localidade dos Estados Unidos [23], a qual atingiu valores milhares de vezes superior ao limite referido acima.

Embora não sejam em geral ameaças globais, os poluentes podem aparecer de onde menos se espera e terem dinâmicas e comportamentos paradoxais que têm de ser encarados de forma global e integrada. Em cidades muito arborizadas, por exemplo, podemos ter poluição devida aos com- postos orgânicos voláteis emitidos pelas árvores que potenciam o aparecimento de ozono troposférico. O movimento das massas de ar leva poluentes para o topo dos Himalaias [24], local onde estes não são produzidos. Quantidades vestigiais (mas não perigosas para os animais) de diclorodifeniltricloroetano (DDT) mantêm-se ainda constantes nos pinguins do Antárctico, embora tenham deixado de aparecer noutros animais, devido provavelmente ao contacto continuado dos pinguins com gelo com DDT acumulado [25]. Vários outros exemplos podem ser analisados. Quando se fala da determinação de quantidades vestigiais - como resultado do aumento do poder das capacidades analíticas da química - devemos verificar se há motivos de preocupação válidos e necessários e não cair no exagero daquilo que se poderia chamar a falácia do microscópio: olhar para algo que vemos ampliado como se fosse realmente enorme e não apenas como um objecto ou número que estamos a ver ampliado e em pormenor.

Existem outras ameaças à sustentabilidade do planeta e do nosso modo de vida que são menos conhecidas, mas não menos importantes, como as quantidades limitadas de alguns elementos (ver, e.g., [26]). De entre esses, o mais crítico é o hélio que se escapa para fora da atmosfera e que é necessário num grande número de equipamentos. Outros exemplos são o neodímio, importante para os magnetes das eólicas e carros eléctricos, índio e gálio, para um grande número de utilidades, e o fósforo, tão necessário na agricultura. No entanto, nestes últimos casos uma reciclagem mais eficiente poderá ser a solução.

Uma questão recorrente é a da capacidade que temos para alimentar todas as pessoas no planeta de forma sustentável (ver, e.g., [27]). Esta questão é complexa, mas talvez menos dramática do que é muitas vezes posta. Devemos além disso olhar para o passado, em particular para o início do século XX. A população crescia de forma exponencial e os recursos agrícolas, em especial os adubos, pareciam estar a esgotar-se. A descoberta dos adubos sintéticos por Haber e Bosch veio, segundo estimativas [5], salvar da fome quase três mil milhões de pessoas. Paralelamente ocorreu um grande aumento da esperança de vida média devido, não só às melhores condições de alimentação como ao tratamento de águas, saneamento, higiene, vacinas e novos medicamentos. Na Figura 3 apresentam-se estimativas de vidas salvas devido a avanços científicos. A vermelho indicam-se aqueles que têm maior relação com a química. Note-se como a invenção dos adubos sintéticos, o tratamento das águas ou as vacinas têm muito maior impacto do que a descoberta dos antibióticos.

Voltando à questão do aumento da população, parecem já haver sinais de abrandamento, e não apenas no ocidente, onde nas últimas décadas está em regressão. Para isso tem concorrido a melhoria das condições de vida, maior liberdade das mulheres e cultura média humanas. Em termos químicos, a revolução dos contraceptivos que ocorreu a partir dos anos 1960 [6], terá provavelmente um contributo decisivo para a estabilização da população.

A esse respeito, tem sido levantada a questão dos estrogénios nas águas, os quais nos EUA se demonstrou re- 


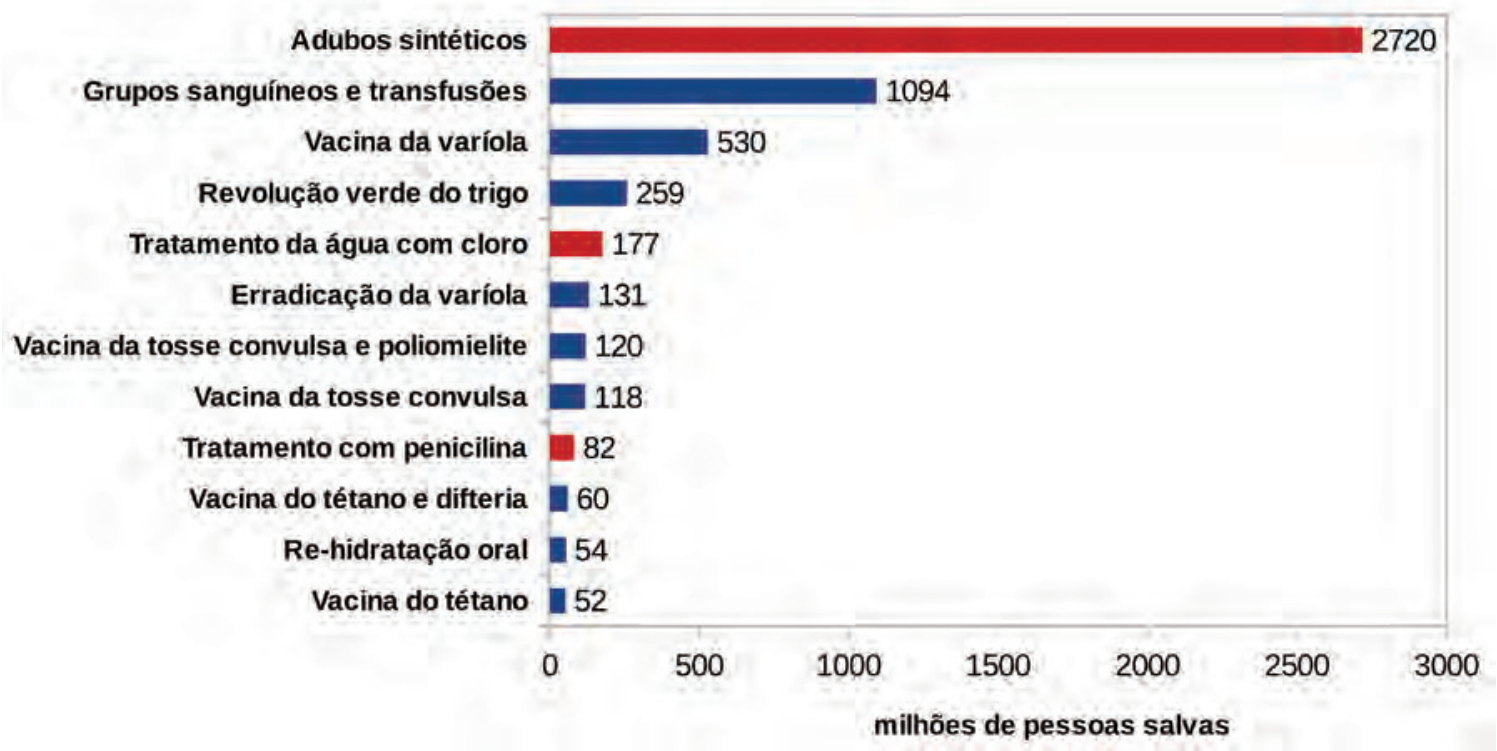

Figura 3 - Estimativa do número de vidas salvas devido a avanços científicos [28]

centemente não terem origem nos contraceptivos orais sintéticos [29]. É preciso notar, como referido acima, que actualmente temos meios de análise muito poderosos que permitem detectar quantidades vestigiais de estrogénios e que, por outro lado, os agregados populacionais grandes acabam por ter uma pressão elevada sobre os cursos de água, através dos sistemas de saneamento. Uma outra revisão recente [30] refere valores inferiores à predicted no-effect concentration de 0,1 ng/L em mais 99\% das águas analisadas. Fonseca et al. [31] analisaram as águas de quatro efluentes de centrais de tratamento de águas residuais portuguesas e detectaram valores da ordem de 0,1-0,7 $\mu \mathrm{g} / \mathrm{L}$ para vários tipos de estrogénios sintéticos. Embora dignas de atenção, estas concentrações estão sujeitas a diluições que as aproximarão dos valores referidos acima. É também de notar que actualmente existem muitos estudos e desenvolvimentos tendentes a neutralizar quantidades vestigiais tanto de estrogénios como de antibióticos e pesticidas nas águas residuais.

\section{NATURAL OU ARTIFICIAL, BIOLÓGICO, QUÍMICO OU HUMANO?}

O escaravelho vermelho é uma praga das palmeiras que as leva à morte. Há um fungo que está a matar as rãs em todo o mundo. O escaravelho longicórneo transporta um nemátodo que mata os pinheiros. O comportamento destes seres naturais mostra-nos que a natureza não é boa nem má. A natureza é como é, e, abandonada a si própria pode seguir caminhos que não nos agradam. Nós humanos, por outro lado, agimos sobre a natureza para a explorar e alterar e também para corrigir situações que identificamos como problemas. Nos casos acima com pesticidas químicos ou tratamentos biológicos.

O desenvolvimento da agricultura moderna com os adubos e pesticidas sintéticos e o melhoramento das espécies permitiu uma muito maior produtividade, de forma a se alimentarem muito mais pessoas, sem que a área cultivada tenha aumentado muito no último século. No entanto, cada uma das palavras da frase anterior tem sido alvo das mais acesas discussões científicas e ideológicas.

A utilização dos adjectivos orgânica ou biológica e química para a agricultura, assim como o comportamento dos agricultores envolvidos, tem muitos aspectos ideológicos [32]. Essa dicotomia é enganadora por não ser simétrica e penaliza de forma desnecessária a química. De facto, a expressão agricultura integrada, que corresponde a um conjunto de (boas) práticas agrícolas obrigatórias por lei, dá actualmente melhor conta da situação. A agricultura biológica tem também um conjunto de práticas e leis associadas e, em alguns casos, é permitido o uso de tratamentos ditos químicos como os do enxofre, caldas de cobre, permanganato, entre outros. Por outro lado a agricultura integrada pode e deve incorporar, sempre que possível (veja-se à frente), as boas práticas biológicas e tem como regra a integração dos tratamentos químicos.

É curioso que a agricultura biológica seja, nos Estados Unidos, cerca de 30\% mais rentável do que a agricultura química, embora a sua produtividade seja pelo menos $30 \%$ mais baixa [32]. É, no entanto, preciso notar que nos Estados Unidos apenas 1\% (e na Europa ainda menos) da agricultura é biológica e que provavelmente um grande aumento desta prática traria problemas de produtividade, aumento dos espaços ocupados, entre outros. Press et al. [32] referem, em particular, a questão da lavra dos terrenos que na agricultura química é mínima para preservar os solos, sendo acompanhada pelo uso de herbicidas, enquanto que na agricultura biológica se faz uma lavra mais profunda e há monda de ervas, actividades que, por um lado, envolvem mais mão-de-obra e pelo outro obrigam a rotatividade e outras práticas que diminuem a produtividade. Para complicar ainda mais o debate, estudos recentes parecem mostrar que não há ganhos de biodiversidade com a agricultura biológica [33].

O debate sobre o uso de herbicidas é muito polarizado, em especial quando se estende às colheitas envolvendo OGM 
(organismos geneticamente modificados), mais em particular plantas que são modificadas geneticamente para resistir a herbicidas como o glifosato (permitido nos EUA, mas não na UE), com grande focagem dos grupos activistas no Roundup da Monsanto. Está fora do âmbito deste texto discutir a problemática complexa dos OGM, embora a consulta da literatura científica pareça mostrar que não existem provas concretas de que os OGM sejam mais nocivos para os humanos do que muitas das plantas naturais que consumimos. No entanto, a partir daí o debate desloca-se para uma multitude de aspectos: o receio legítimo de contaminações genéticas futuras, dado que muitos microorganismos podem trocar material genético com os OGM ao mesmo tempo que têm uma evolução biológica rápida, o controlo da propriedade intelectual das sementes de OGM e o controlo supostamente exercido sobre os agricultores e colheitas, a hipotética ligação entre o autismo e o glifosato, entre muitos outros aspectos que têm sido alvo de abundante literatura e debate público e científico.

O glifosato foi associado ao autismo (veja-se, e.g., [34]). Mas o autismo tem também sido "associado" a muitas outras coisas (basta consultar a internet para encontrar dezenas de possibilidades) como a alimentação com glúten, as ecografias, as vacinas (associação com efeitos sociais catastróficos e, sabe-se agora, incorrecta), o mercúrio e até o uso de perfumes. O problema destas associações é que correlação não significa causalidade e que para piorar as coisas os dados usados são por vezes enviesados de forma consciente ou inconsciente com base nas crenças dos autores. Cory Doctorow [35] mostra, por exemplo, no seu blogue, usando dados públicos, que se pode associar o autismo ao consumo de alimentos de agricultura biológica!

A literatura científica e os relatórios técnicos sobre os OGM e o glifosato são inúmeros, sendo impossível de os resumir neste texto. No entanto, como em todos os assuntos delicados que aqui refiro, é necessário espírito crítico e analisar as fontes originais e verificar a sua credibilidade com o máximo cuidado. A generalidade dos estudos mostra que o glifosato é um pesticida que não apresenta riscos significativos para os humanos [36] e que não apresenta efeitos mensuráveis no sistema reprodutor [37], mas é possível encontrar estudos que afirmam o contrário, ou que levantam essa possibilidade (o que não é o mesmo que confirmá-lo). Há, no entanto, que referir que este assunto levanta alguma preocupação a que a União Europeia tem estado atenta. Um trabalho de Séralini et al. [38] que apontava para efeitos tóxicos de longo prazo dos OGM foi retirado pela revista original - embora republicado em 2014 noutra [38] - contra a vontade dos autores, depois de bastante discussão, e com a falta de aprovação da comunidade científica (veja-se e.g. Portier et al. [39]), por não haver indícios de fraude ou má conduta por parte dos autores.

Muitos dos actuais pesticidas são baseados em compostos naturais. Os neonicotinóides na nicotina do tabaco, os piretróides nas piretrinas dos crisântemos, entre muitos outros.
Mais uma vez é impossível resumir aqui toda a bibliografia e dados técnicos existentes sobre o assunto. Actualmente, os pesticidas são aprovados de forma condicional e só podem ser usados em condições muito específicas e reguladas. E é obrigatório que o seu uso seja realizado em regime de protecção integrada. Para serem aprovados têm de ter tempos de persistência no ambiente limitados e ter toxicidade controlada e conhecida. Os pesticidas que são especialmente tóxicos para os organismos marinhos são proibidos junto de cursos de água. E quando se descobre uma toxicidade particular (e.g., para com as abelhas) são retirados do mercado.

A seguir à fome e má nutrição, a malária é actualmente a maior causa de morte no mundo [40]. E já foi assim no século XX, em que ultrapassou as vítimas das guerras e da febre pneumónica. Até meados do século Xx a malária esteve presente nas regiões temperadas junto aos rios em Portugal e Itália, por exemplo. Para combater esta doença recorre-se a medicamentos e à eliminação do mosquito portador. No que concerne aos medicamentos usou-se inicialmente a quinina e actualmente usam-se misturas de cloroquina e artemisinina. No entanto, o microrganismo tem ganhado resistências e começa a ser urgente encontrar novos medicamentos. No que respeita ao mosquito, a drenagem dos pântanos e especialmente o uso de insecticidas foi fundamental. De entre estes, o famoso DDT foi o principal responsável pelo desaparecimento do mosquito nas regiões temperadas. Entretanto exagerou-se no uso do DDT e outros insecticidas, o que foi denunciado por Rachel Carson em "Primavera Silenciosa" [3]. A indústria química reagiu de forma desproporcionada e as posições extremaram-se, tornando-se difícil avaliar correctamente a situação. Na verdade, não há hoje dúvida de que o uso do DDT e outros insecticidas era de facto até aos anos 1960 exagerado. No entanto, a diabolização e banimento do DDT privou, em parte, o mundo de um insecticida que sabemos hoje não é tão perigoso como apresentado na altura (veja-se, e.g., [6]). E muitos anos depois da publicação do livro ainda encontramos autores que vêm em Primavera Silenciosa e na diabolização do DDT uma fraude científica que teve enormes custos humanos [41]. No entanto, nos anos 1960 o mosquito começava já a apresentar resistência ao DDT e por isso a sua utilidade começava a ser limitada. Também a sua elevada persistência (da ordem das dezenas de anos) nos solos, águas e gelo nos faz ter a certeza de que o tempo do DDT passou.

Primavera Silenciosa é um livro ainda muito citado (embora pouco lido) que é apresentado como a obra fundadora do movimento ecologista moderno. Para além da retórica e de algum exagero, ou dados ultrapassados, encontramos em Carson [3] afirmações que poderiam estar num qualquer manual de agricultura e protecção integrada: Não me proponho afirmar que os insecticidas químicos nunca devem ser usados. Mas afirmo que pusemos produtos químicos de grande potencial venenoso e biológico, de forma indiscriminada, nas mãos de pessoas ignorantes da sua capacidade de causar danos [...].

Sociedade Portuguesa de Química | Tel.: 217934637 Fax: 217952349 / 211316639 | E-mail: sede@spq.pt 


\section{A químICA QUE Só VEMOS QUANDO ALgO PARECE CORRER MAL}

A partir dos anos sessenta a indústria química mundial abandonou o optimismo, sentiu-se como que injustiçada e procurou tornar-se invisível, já que continuava a ser imprescindível. Por exemplo [2], o slogan da Dupont que era Better things for better living ...through chemistry perdeu o ...through chemistry, em 1982, ficando apenas Better things for better living e tornou-se, a partir de 1999, The miracles of science. A química, como ciência, começou também a sofrer os efeitos dessa invisibilidade e da hostilidade inconsciente do público. Químico tornou-se sinónimo de algo venenoso, que faz mal e que não é natural. A comunicação social e muitos dos ecologistas de serviço (alguns deles sociólogos ou da área da literatura) fazem o mesmo. $\mathrm{E}$ no entanto as coisas mais venenosas que conhecemos não são artificiais, são naturais, como a toxina do botulismo. Os aditivos alimentares são testados e controlados e, quando se verifica que causam alergias, são banidos ou é incluído no rótulo essa informação.

Há muita informação negativa a circular sobre compostos (químicos) em geral. Mas quando a informação é positiva já não são químicos: são vitaminas, hormonas, produtos naturais, antioxidantes; às vezes uma molécula com um adjectivo ou outras formas de evitar a palavra química.

As quantidades vestigiais de tudo são rigorosamente controladas e isso leva-nos a uma espécie de paradoxo da informação relacionado com a falácia do microscópio. Quanto mais sabemos sobre uma coisa mais parecemos temê-la. Saber que um alimento tem isto ou aquilo é melhor que não saber que tem uma bactéria perigosa!

As nossas capacidades analíticas são hoje tão precisas que podemos chegar a resultados incríveis. O que vemos não é a ponta de um iceberg, é um cristal de gelo aumentado! Mais de metade das notas americanas apresentavam num estudo vestígios de cocaína! Um outro estudo permitiu associar toxinas ambientais ao estatuto socioeconómico [42]: os ricos têm mais mercúrio devido às ostras e os pobres cádmio e vestígios de plásticos.

Aspectos particulares e relativamente menores são importantes, e não raras vezes elucidativos, para procurarmos entender o nosso mundo e projectar o futuro. Muitos dos debates centram-se em assuntos irrelevantes ou são monopolizados por não-especialistas e por pessoas com demasiadas certezas, quando em geral sabemos muito menos do que acreditamos saber. Um exemplo de uma polémica recente é o dos polifosfatos (Figura 2, 3) na conservação de peixe, em especial de bacalhau, assunto sobre o qual existe razoável bibliografia especializada. Refiro aqui apenas que se trata de um polímero natural que existe nas células [43] e que o problema parece ser mais económico (o peixe demora mais tempo a secar) do que de saúde ou ambiental. A internet e os media abundam de alarmes exagerados e supostos perigos. A isso juntam-se os nossos preconceitos, crenças e gostos. Por exemplo, o peixe de aquicultura pode ser menos saboroso do que o peixe selvagem e ser alimentado com comida processada, mas é potencialmente mais sustentável que a pesca de arrasto intensiva. Ainda há pouco tempo circulava mais um aviso sobre os perigos do salmão de aquicultura que era alimentado com um composto derivado do petróleo, que obviamente só poderia ser cancerígeno. Analisada a questão verifica-se ser um composto antioxidante natural presente nos camarões e outros animais - a astaxantina (Figura 2, 4) - em nada diferente do natural, senão que é obtido de forma semi-sintética. E se este composto pode ser suspeito de ser cancerígeno ou tóxico, é-o tanto como o de origem natural. Na verdade, a natureza abunda de compostos tóxicos naturais. E quanto à obtenção sintética de compostos que existem na natureza, esse é em geral um caminho sustentável, como referido acima. A maior parte da vitamina C, vanilina (responsável pelo aroma a baunilha) e muitos outros compostos que usamos é de origem sintética.

Na sequência da apresentação foi colocada a questão pertinente de onde encontrar informação fidedigna sobre aditivos, conservantes e compostos químicos que estejam presentes, por exemplo, em formulações, ou que nos tenham dito (em geral em e-mails alarmistas sem fundamento) que são nocivos ou até muito bons para qualquer coisa. Primeiro, se o composto é suspeito já foi alvo, com certeza, de um grande número de estudos, artigos científicos ou relatórios e estes aparecem normalmente na internet. Revistas científicas, ou organizações como a FDA e a UE são em geral de confiança, mas é preciso espírito crítico e paciência. Também a Wikipedia, especialmente se acompanhada de citações fidedignas, pode ser uma fonte de informação (a usar com espírito crítico também). Se só aparecem dados em blogues, fóruns de discussão ou até no Facebook, ou outras redes sociais (e com links para páginas sem credibilidade) dificilmente a informação terá algum fundamento. A UE tem um sítio com informações sobre produtos químicos e ambiente, o REACH (http://ec.europa.eu/environment/ chemicals/reach/reach_en.htm).

\section{Conclusões}

Os aspectos químicos complexos e controversos que nos rodeiam podem ser abordados de forma pessimista ou optimista mesmo (e principalmente) se estivermos na presença de dados objectivos e quantitativos. $\mathrm{O}$ autor deste texto, acredita que a abordagem optimista (embora realista e crítica) é com certeza a mais sensata. No que concerne ao aspecto particular dos denominados produtos químicos, devemos evitar a falácia do microscópio atribuindo mais importância aos aspectos qualitativos (por exemplo, ter sido detectada uma determinada toxina) que aos aspectos quantitativos (a concentração da toxina ser tão baixa que não tem qualquer efeito). Em termos gerais, a química continuará a ter um papel importante na resolução de muitos dos problemas que o nosso mundo enfrenta hoje e na criação de novas soluções. Por exemplo, através de modos de obter e armazenar energia de forma mais eficiente e sustentável e da descoberta ou invenção de novos medicamentos e materiais. Para além dos clássicos 3R da Redução, 
Reutilização e Reciclagem, a química, através da Química Verde, tem ainda para oferecer mais $2 \mathrm{R}$ a Reformulação dos processos e os Recursos alternativos.

\section{AgradeCIMENTOS}

Agradeço o financiamento da Fundação para a Ciência e a Tecnologia através do Centro de Química de Coimbra (Unidade 313). Agradeço também às Professoras Celeste Gomes e Isabel Abrantes o convite para o encontro que originou este texto.

\section{REFERÊNCIAS}

[1] S.P.J. Rodrigues, "Jardins de Cristais. Química e Literatura”, Gradiva, Lisboa, 2014

[2] B. Bensaude-Vincent, J. Simon, "Chemistry: The Impure Science”, $2^{\text {nd }}$ Revised edition, Imperial College Press, London, 2012. Uma parte das problemáticas discutidas no presente texto são abordadas com muito mais pormenor neste livro.

[3] R. Carson, "Primavera Silenciosa”, Pórtico, Lisboa, 1962

[4] J. Emsley, "Vanity, Vitality, and Virility: The Science behind the Products You Love to Buy”, Oxford University Press, Oxford, 2004

[5] B. Woodward, J.N. Shurkin, D. Gordon, “Scientists greater than Einstein: the biggest lifesavers of the twentieth century”, Quill Driver Books, Fresno, 2009. Informação adicional no sítio http://www.scienceheroes.com (acedido a $5 / 1 / 2016)$

[6] P. Le Couteur, J. Burreson, "Napoleon's buttons - 17 molecules that changed history", Jeremy Tarcher/Penguin, New York, 2003

[7] J. Schummer, B. Bensaude-Vincent, B. Van Tiggelen, "The Public Image of Chemistry”, World Scientific Publishing, Singapore, 2007

[8] Royal Society of Chemistry, "Public attitudes to chemistry”, Relatório disponível no sítio http://www.rsc.org/campaigning-outreach/campaigning/public-attitudes-chemistry/ (acedido a 2/10/2015)

[9] B. Lomborg, "The Skeptical Environmentalist: Measuring the Real State of the World”, Cambridge University Press, Cambridge, 2001. Pesando todas as críticas e discussões sobre este livro (vejam-se, por exemplo, as referências da Wikipedia, http://en.wikipedia.org/wiki/_The_Skeptical_ Environmentalist, acedido a 5/1/2016, este é um razoável ponto de partida para a análise global do estado real do mundo.

[10] J. Calado "Limites da Ciência”, Fundação Francisco Manuel dos Santos, Lisboa, 2014

[11] Francisco, "Encíclica «Laudato si' - sobre o cuidado da casa comum»”, Paulinas Editora, Lisboa, 2015

[12] M. Eriksen, L.C. Lebreton, H.S. Carson, M. Thiel, C.J. Moore, J.C. Borerro, F. Galgani, P.G. Ryan, J. Reisser, PLoS ONE 9 (2014) e111913

[13] A.L. Andrady, Marine Pollution Bull. 62 (2011) 1596-1605
[14] P.T. Anastas, T.C. Williamson (eds.) "Green Chemistry: Frontiers in Benign Chemical Synthesis and Processes", Oxford University Press, Oxford, 1998

[15] P.J. Scheuer, J. Chem. Ed. 76 (1999) 1075-1079

[16] Dados da Wikipedia: https://en.wikipedia.org/wiki/List_ of_oil_spills (acedido a 5/3/2015)

[17] R. Hunt, Chemistry in Britain, November, 1995, 874

[18] União Europeia, "Removal and disposal of disused offshore oil and gas installations”, disponível em http://eur-lex. europa.eu/legal-content/PT/TXT/?uri=URISERV:128053 (acedido a 21/8/2015)

[19] M. Soares, "Polvos, safios e bogas vivem em paz a bordo de quatro navios de guerra”, Jornal Público, 21 de Setembro de 2014, http://www.publico.pt/local/noticia/polvos-safiose-bogas-vivem-em-paz-a-bordo-de-quatro-navios-de-guerra-1670247 (acedido 21/8/2015)

[20] M. Ball, M. Wietschel, "Hydrogen Economy, Opportunities and Challenges”, Cambridge University Press, Cambridge, 2010

[21] W.R.L. Anderegg, J.W. Prall, J. Harold, S.H. Schneider, Proc. Natl. Acad. Sci. 107 (2010) 12107-12109

[22] J.R. McConnell , O.J. Maselli, M. Sigl, P. Vallelonga, T. Neumann, H. Anschütz, R.C. Bales, M. A.J. Curran, S.B. Das, R. Edwards, S. Kipfstuhl, L. Layman, E.R. Thomas, Sci. Rep. 4 (2014) Article 5848

[23] D.H. Gorski, "How the Michigan state government poisoned the children of Flint", http://scienceblogs.com/insolence/2016/01/08/the-poisoning-of-the-children-of-flintmichigan/ (acedido a 8/1/2016)

[24] J. Qiu, "Organic pollutants poison the roof of the world", Nature News, 11 April 2013, http://www.nature.com/news/ organic-pollutants-poison-the-roof-of-the-world-1.12776 (acedido a 5/1/2015)

[25] N. Lubick, Environ. Sci. Technol. 42 (2008) 3909

[26] E. Davies, Chemistry World, January 2011, 50-54

[27] J. Foley, Can we feed the world \& sustain the planet? Scientific American, November 2011, 60-65

[28] Dados do sítio http://www.scienceheroes.com (acedido a 24/6/2015)

[29] A. Wise, K. O'Brien, T. Woodruff, Environ. Sci. Technol. 45 (2011) 51-60

[30] J.P. Laurenson, R. A. Bloom, S. Page, N. Sadrieh, AAPS J. 16 (2014) 299-31

[31] A.P. Fonseca, S. Massano Cardoso, W.I. Esteves, Conference Paper at CEF 2013, Coimbra, 27 November 2013

[32] M. Press, E.J. Arnould, J.B. Murray, K. Strand, J. Marketing 78 (2014) 103-119

[33] M.K. Schneider, G. Lüscher, P. Jeanneret, M. Arndorfer, Y. Ammari, D. Bailey, K. Balázs, A. Báldi, J.-P. Choisis, P. Dennis, S. Eiter, W. Fjellstad, M.D. Fraser, T.Frank, J.K. Friedel, S. Garchi, I.R. Geijzendorffer, T. Gomiero, G. Gonzalez-Bornay, A. Hector, G. Jerkovich, R.H.G. Jongman, E. Kakudidi, M. Kainz, A. Kovács-Hostyánszki, G. Moreno, C. Nkwiine, J. Opio, M.-L. Oschatz, M.G. Paoletti, P. Pointereau, F.J. Pulido, J.-P. Sarthou, N. Siebrecht, D. 
Sommaggio, L.A. Turnbull, S. Wolfrum, F. Herzog, Nature Comm. 5 (2014) 5151

[34] A. Samsel, S. Seneff, Interdiscip. Toxicol. 6 (2013) 159-184

[35] C. Doctorow, Correlation between autism diagnosis and organic food sales, http://boingboing.net/2013/01/01/correlation-between-autism-dia.html (acedido a 30/7/2015)

[36] G.M. Williams, R. Kroes, I.C. Munro, Regul. Tox. Pharmacol. 31 (2000) 117-165

[37] A.L. Williams, R.E. Watson, J.M. DeSesso, Health B Crit. Rev. 15 (2012) 39-96

[38] G.E. Séralini, E. Clair, R. Mesnage, S. Gress, N. Defarge, M.
Malatesta, D. Hennequin, J.S. de Vendômois, Food Chem. Toxicol. 50 (2012) 4221-4231. (Retracted by the Editor); Republicado: Environmental Sciences Europe 26 (2014) 14-24

[39] C.J. Portier, L.R. Goldman, B.D. Goldstein, Environmental Health Perspectives 122 (2014) A36

[40] D.J. Krogstad, Epidem. Rev. 18 (1996) 77-89

[41] J.G. Edwards, J. American Physic. Surg. 9 (2004) 83-88

[42] J. Tyrrell, D. Melzer, W. Henley, T.S. Galloway, N. J. Osborne, Environ. Int. 59 (2013) 328-35

[43] A. Kornberg, J. Bacterology 177 (1995) 491-496

\section{Actualidades Científicas}

\section{DendRíMEROS DE GLICOFULERENOS NO COMBATE À INFECCÇÃO DO VIRUS ÉBOLA}

Dendrímeros baseados no fulereno $\mathrm{C}_{60}$, solúveis em água e biocompatíveis, podem impedir a infecção de células pelo vírus Ébola.

O sistema imunitário dos animais pode ser alertado para um ataque por um vírus quando este se liga a receptores de glicoproteína na superfície de algumas células. Isto desencadeia uma resposta imunitária para prevenir a infecção. No entanto, certos vírus como o VIH e Ébola ligam-se ao receptor e usam-no como uma forma de se infiltrar na célula, contornando o sistema imunológico.

É possível evitar que o vírus penetre numa célula ligando o receptor a uma outra molécula com a qual possua maior afinidade. Dendrímeros contendo açúcares têm sido estudados para a ligação a receptores-alvo. Uma equipa de investiga-

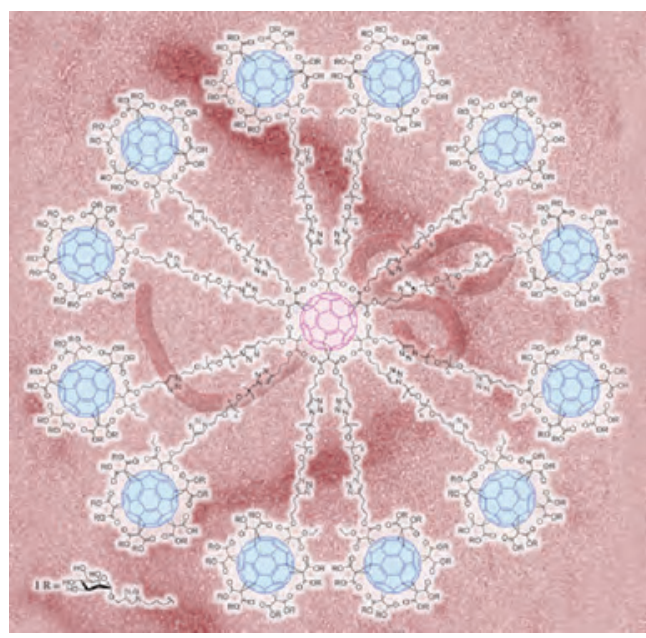
dores da qual faz parte Nazario Martín da Universidade Complutense de Madrid sintetizou dendrímeros deste tipo baseados no fulereno $\mathrm{C}_{60}$. As moléculas obtidas possuem uma estrutura molecular globular que imita a forma de muitos vírus e têm uma boa capacidade de ligação aos receptores-alvo. Testes in vitro mostraram que as estruturas obtidas, usadas em muito baixa concentração, eram potentes inibidores da infecção pelo vírus Ébola.

(adaptado de “'Superballs' can block infection by Ebola virus”, http:// www.rsc.org/chemistryworld/2015/11/fullerene-dendrimers-preventebola-virus-infection e de A. Muñoz, D. Sigwalt, B.M. Illescas, J. Luczkowiak, L. Rodríguez-Pérez, I. Nierenarten, M. Joller, J.S. Remy, K. Buffet, S.P. Vincent, J. Rojo, R. Delgado, J.F. Nierengarten, N. Martín. Nat. Chem., (2015), DOI:10.1038/nchem.2387)

\section{QUÍMICA}
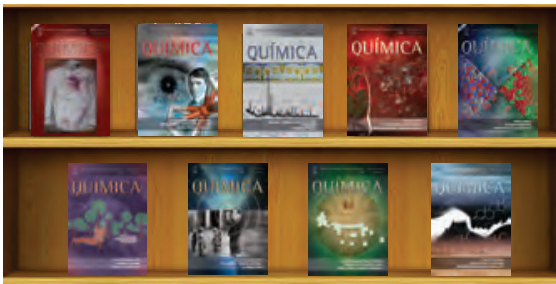
o Boletim trimestral que apresenta a VISÃO dos QUÍMICOS PORTUGUESES

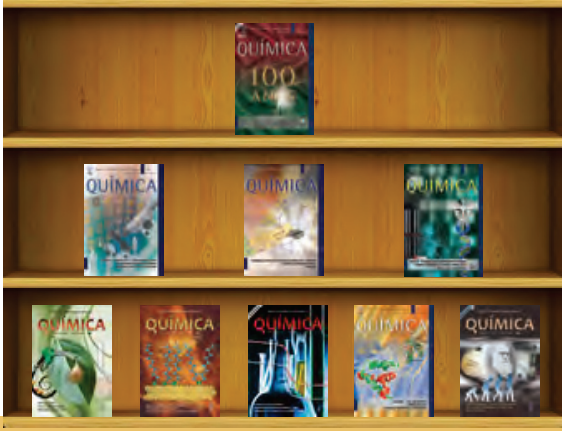




\section{Antoine-Laurent LAVOISIER}

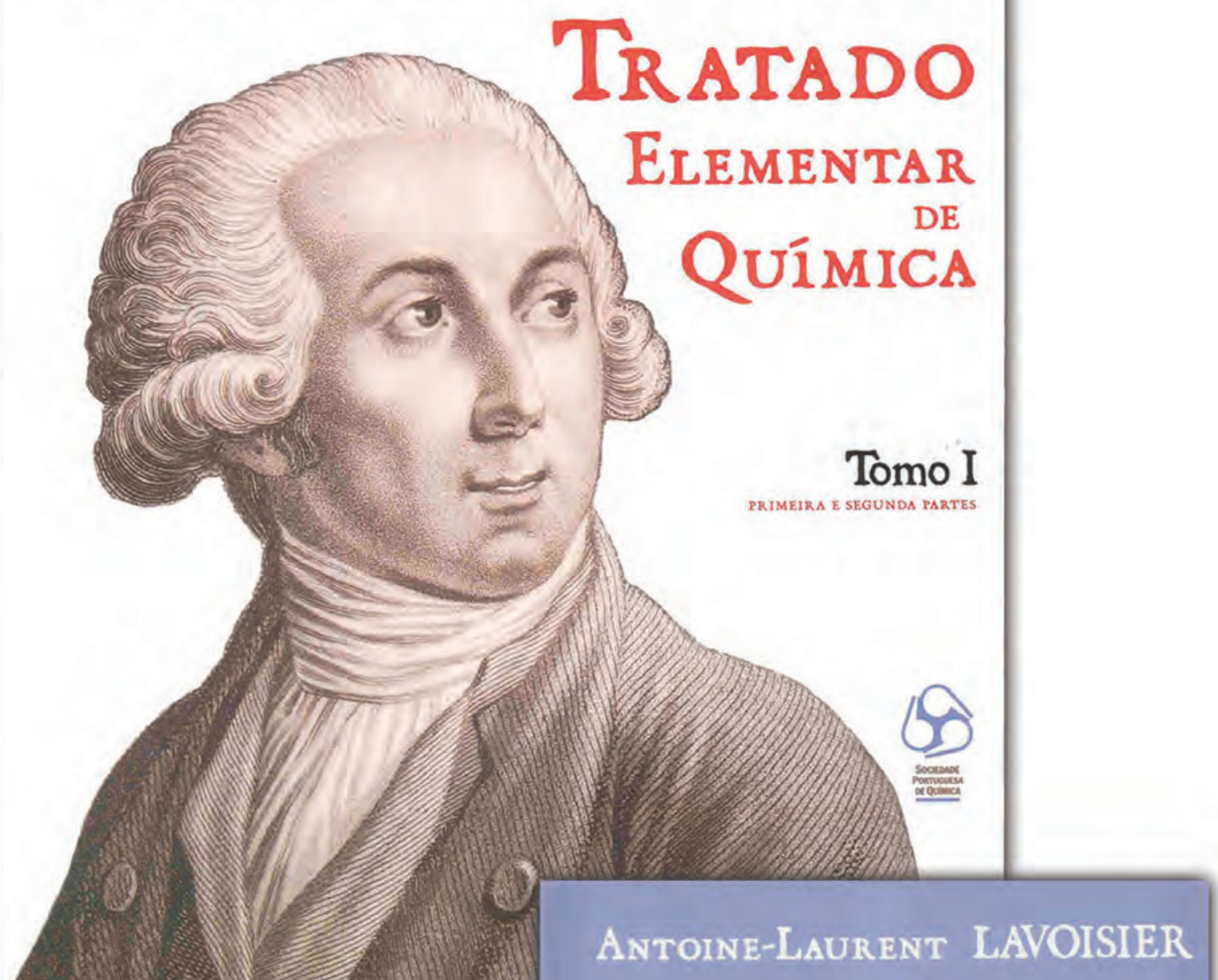

0 «Tratado Elementar de Química» de Antoine-Laurent Lavoisier (1743-1794), publicado em Paris em 1789, é um dos grandes clássicos da Química. Escrito na nova nomenclatura proposta também por Lavoisier, em conjunto com Morveau, Berthollet e Fourcroy, é a primeira obra de química moderna, abandonando-se as inadequadas designações de raízes alquímicas e a desacreditada teoria do flogisto. No tratado, ilustrado pela mulher do autor, Marie-Anne-Pierrette Paulze Lavoisier, formula-se de forma clara a conservação da matéria e define-se elemento químico de forma operacional.

No centenário da fundação da Sociedade Portuguesa de Química, publica-se finalmente uma cuidada tradução portuguesa do «Traité», modernizada e anotada.

TOMO I e II

P.V.P.: 32 euros

Sócios da SPQ: 20 euros
ENCOMENDAS À SPQ

Av. da República 45, $3^{\circ}$ esq - 1050-187 Lisboa

Telefone: 217934637 email: sede@spq.pt 